\title{
ANALYSIS FOR MAPPING OF BUILT-UP AREA USING REMOTELY SENSED INDICES \\ - A CASE STUDY OF RAJARHAT BLOCK IN BARASAT SADAR SUB-DIVISION IN WEST BENGAL (INDIA)
}

\author{
Debashish Kumar GHOSH ${ }^{1}$, ANukUl CH MANDAL ${ }^{1}$, Raja MAJUMder ${ }^{1,2}$, \\ POLY PATRA ${ }^{1}$, GOURI SANKAR BHUNIA ${ }^{1 *}$ \\ ${ }^{I}$ Department of Geography, Seacom Skills University, Kendradangal, Santiniketan, \\ Birbhum - 731236, West Bengal \\ ${ }^{2}$ Dinabandhu Mahavidyalaya, Bongaon, North 24 Parganas, West Bengal \\ *Corresponding authore-mail: rsgis_gouri@rediffmail.com
}

Received: $17^{\text {th }}$ November 2017, Accepted: $1^{\text {st }}$ August 2018

\begin{abstract}
Present study investigated mapping and monitoring urban land areas from Landsat8 satellite data using remotely sensed indices. The normalized difference built-up index (NDBI), Enhanced Built-Up and Bareness Index (EBBI), Index-based built-up index (IBI), urban index (UI), normalized difference bareness index (NDBaI) were used to extract the built-up area. The NDBI was more effective at discriminating built-up areas and at increasing accuracy (overall accuracy of $76.45 \%$ and kappa accuracy of $57 \%$ ) of the built-up density percentage than other remotely sensed indices. Evidence on built-up area change geographically would permit urban planner and decision makers to comprehend and appraise urban growth pattern in regards to land cover dynamics.
\end{abstract}

Keywords: Remotely sensed indices, Built-up, land use dynamics

\section{INTRODUCTION}

Mapping the built up areas is important because the existence of these types of land can be used as an indicator of urban development and urban sprawl. Increasing population has imposed the increase of huge demands for new housing, schools, transportation and other basic civic amenities. This condition has been criticized due to high surface run-off (As-syakur et al., 2012), urban heat island (He et al., 2010), water and air pollution (Melesse et al., 2007). The physical jargons and configurations of urban areas on landscapes can be perceived, mapped and investigated using geospatial technology (Gadal et al., 2009). Symmetrical growth of urban centers consumes agricultural land adjacent to these, resulting in lower agricultural productivity. The Barasat sadar sub-division is still young and the regionis pointing towards the rampant and uncontrolled growth of built-up areas for last 2-3 decades.

In recent years, understanding the dynamics of sprawl, quantifying them and subsequently predicting the same for a future period has attracted significant interest of researchers and scientist (Kumari \& Shekhar, 2016; Tamilenthi et al., 2011). Measurements of these mannerisms and additional attributes are used to improve consistent indices of urban 
expansion. The mapping process applies various remotely sensed data and spectral values on the land use classes. Some researchers have employed an array of indicators, such as the normalized difference built-up index (NDBI) (Zha et al., 2003), Index-based built-up index (IBI) (Xu, 2008), urban index (UI) (Kawamura et al., 1996), normalized difference bareness index (NDBaI) (Zhao \& Chen, 2005), and Bare soil index (BI) (Rikimaru, 1997) for mapping the built up areas. He et al., (2010) and Sukristiyanti et al., (2007) indicated that NDBI and UI are feeble to corroborate the dissemination of built-up areas. This is due to the high intricacy of the spectral distribution outlines to vegetation, bare land, and built-up areas, essentially in terms of the pixel amalgamations in areas with heterogeneous substances. Furthermore, Eryilmaz et al., (2008) concentrated on assessing urban expansion through the practice of population data and comprehensive land use/land cover pattern.

Paul \& Chatterjee (2012) suggested the sharply increase of urban growth pattern of Rajarhat block during the period between 1991 (7.13\%) and 2001 (14.03\%). Rahaman (2018) also stated that the population growth rate pattern in Rajarhat municipality $14.81 \%$ during the period between 2001 and 2011. In the current study, an attempt has been made to study the urban expansion of Rajarhat block (Barasat sadar sub-division, West Bengal, India) using remotely sensed indices. The mapping results have been matched with different remotely sensed indices to ascertain the built-up areas and also provide a clue to determine more accurate remote sensing index for built-up area growth pattern.

\section{STUDY AREA}

The study was conducted in Rajarhat block (Barasat sadar sub-division, West Bengal, India), extended between north latitude and east longitude $\left(22^{\circ} 30^{\prime} 32^{\prime \prime} \mathrm{N}\right.$ to $22^{\circ} 38^{\prime} 03^{\prime \prime} \mathrm{N}$ and $88^{\circ}$ $26^{\prime} 29^{\prime \prime} \mathrm{E}$ to $88^{\circ} 32^{\prime} 57^{\prime \prime} \mathrm{E}$ ), with an areas of $69.09 \mathrm{~km}^{2}$. The area is covered with alluvial sediments of quaternary age, deposited by the river Hooghly and its tributaries. Lithologically, the area is covered by basal clay bed and a top clay bed. The slope of the area is gentle southerly with an average elevation of 9 to 10 metres above mean sea level (MSL). The soil of the study area is purely azonal soil, silty and clayey in texture. Most of the soils are Entisols (younger alluvial soil) and Alfisol (deltaic alluvial soil). The climate of the study area is influenced by monsoon activity (Middey \& Kaware, 2016), comprises with monthly average temperature of about $27.5^{\circ} \mathrm{c}$ and monthly annual rainfall of about $1029 \mathrm{~mm}$ (http://wbdmd.gov.in/writereaddata-/uploaded/DP/North\%2024\%20parganas.pdf). In 2001, the population of the Rajarhat block was 152110 and reached 189893 people in 2011, with annual growth rate of $2.48 \%$ per year. The population density $\left(2,445\right.$ persons $\left./ \mathrm{km}^{2}\right)$ is much greater than the state average of 1,029 population per $\mathrm{km}^{2}$ and it orders $3^{\text {rd }}$ in terms of population density. 
Fig. 1: Location map of the study area

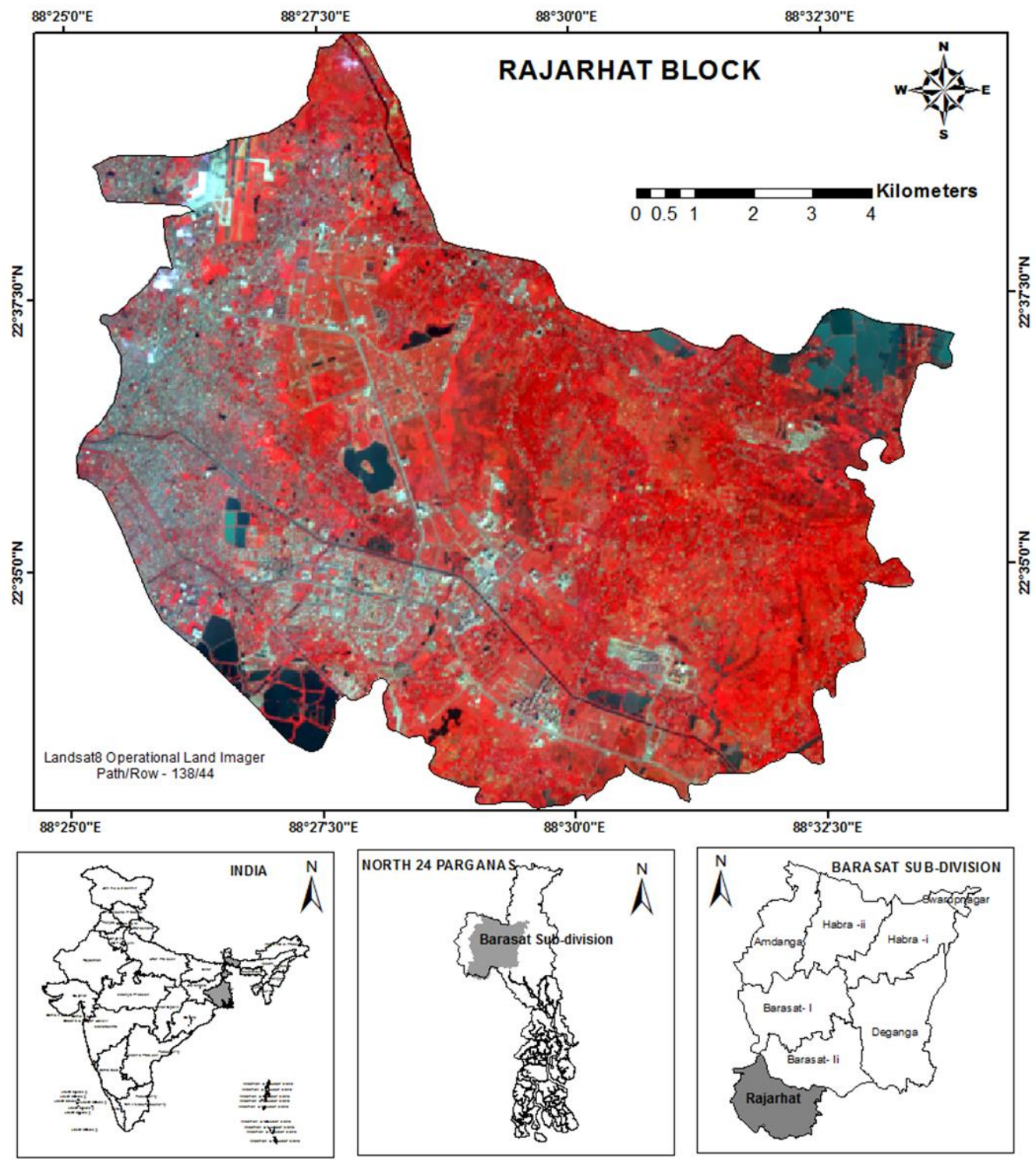

\section{MATERIAL AND METHODS}

\section{Database preparation and processing}

The administrative boundary map of Rajarhat block was obtained from the Census of India 2011 data (http://www.censusindia.gov.in/2011census/dchb/1911_PART_B_DCHB_ NORTH\%20-TWENTY\%20FOUR\%20PARGANAS.pdf). The remote sensing data used in this study was Landsat-8 Operational Land Imager (OLI) of $2016(30 \mathrm{~m} \times 30 \mathrm{~m})$ at path (138) and row (44). The satellite data were attained from the USGS Earth Explore community (https://www.usgs.gov/software/earth-explorer-ee). The accuracy level of the analyses 
Ghosh K. D., Ch Mandal A., Majumder R., Patra P., Bhunia S. G.: Analysis for mapping of built-up area using remotely sensed indices

performed using several remote sensing indices were compared to the distribution of land use in the Google Earth images.

To determine the progressive characteristics of land use/land cover characteristics satellite imageries were assimilated from different phases of time. The satellite imageries were processed using image processing software - ERDAS Imagine version 9.0. All the imageries were geo-referenced on Universal Transverse Mercator (UTM) projection system and World Geodetic System (WGS) 84 datum using image to image registration system in image processing software. After that all the images were subset through clipping and subsetting method based on the study area boundary.

\section{Comparative analysis of remote sensing indices}

The EBBI index was applied using the wavelengths of $0.83 \mu \mathrm{m}, 1.65 \mu \mathrm{m}$, and $11.45 \mu \mathrm{m}$ (NIR, SWIR and TIR respectively) to Landsat images. These wavelengths were nominated based on the contrast reflection range and absorption in built-up and bare land areas. Band ${ }_{5}$ and band $_{6 \text { and }} 7$ of Landsat8 OLI corresponds to NIR and SWIR wavelengths are associated with a high contrast level for detecting built-up and bare land areas (Li et al., 2017). Moreover, in bands 5, 6 and 7, there is an inverse reflection ratio pertaining to distinguish built -up land areas (As-syakur et al., 2012). Vegetation has a high reflectance in $\mathrm{band}_{4}$, but the reflectance of built-up in band is low. In contrast, in band $_{5}$, there is high reflectance when detecting built-up areas compared with vegetated areas (Bhatti \& Tripathi, 2014). Zha et al. (2003) used NIR and SWIR were used for mapping built up areas. The high and low levels of albedo in built-up areas were determined through TIR channel. According to Weng (2008), the employment of TIR channels is very operative for diagramming built-up areas reliant on a low albedo which eradicates the influence of obscurities and water, while a high albedo determines built-up areas evidently. The temperature of a built-up area is 10-12 degrees higher than that of a vegetation (Weng et al., 2004). Consequently, the amalgamation of NIR, SWIR and TIR wavelengths creates it conceivable to mend the plotting method for built-up areas relation to earlier existing remote sensing indices.

The remotely sensed indices were used for quickly mapping built-up areas. The EBBI applies a root function to cluster the numbers that contrast identical objects based on the different levels of reflectance values (As-syakur et al., 2012). The EBBI s calculated from the image data using the following equation:

$$
E B B I=\frac{\left(\text { Band }_{7}-\text { Band }_{5}\right)}{10 \sqrt{\left(\text { Band }_{7}+\text { Band }_{11}\right)}}
$$

EBBI analysis were compared to the results of other remote sensing indices: IBI, NDBI, UI, and NDBaI. The equation of each indices are as follows:

$$
\begin{gathered}
N D B I=\frac{\text { Band }_{6}-\text { Band }_{5}}{\text { Band }_{6}+\text { Band }_{5}} \\
U I=\frac{\text { Band }_{7}-\text { Band }_{5}}{\text { Band }_{7}+\text { Band }_{5}} \\
N D B a I=\frac{\text { Band }_{6}-\text { Band }_{11}}{\text { Band }_{6}+\text { Band }_{11}}
\end{gathered}
$$




\section{Data validation}

The validation method was consummate by associating built up areas dogged by indices (EBBI, IBI, NDBI, UI and NDBaI) with the outcome from Landsat images. The best index for this research is recognized by accuracy testing with field sampled data and high resolution Google images. In this study, 30 samples were randomly selected and verified with the Google earth image and the field to match the exactitudes of built-up extraction from different indices and to appraise the variance between them. The mapping truths were described in the form of overall accuracy (OA) and kappa co-efficient $\left(\mathrm{K}^{\wedge}\right)$ (Sinha et al., 2016).

\section{RESULTS}

The focus of Rajarhat city which is the thickest built-up area is feast within a radius of $5 \mathrm{~km}$. The remaining settlements are spread intermittently around this center upto distance of $10 \mathrm{~km}$. The new patches of built up areas were detected in the south-west part of the sub-division. The sub-division had been rambling away from the central area and the fringe nuclear patches of the settlements.

The transformation of bands 5, 6, 7 and 11 of Landsat8 OLI was examined in this study. Present study investigated the mapping of built up by different transformation indices using satellite data and the use of threshold value as a reference index to distinguish the built-up areas (Table 1). In addition, the results of areal distribution of built-up area compared derived through various indices.

Table 1: Limitation of the index value for each type of index transformation in determining built-up areas.

\begin{tabular}{|l|c|}
\hline \multicolumn{1}{|c|}{ Remote sensing indices } & Built up area \\
\hline EBBI (Enhanced Built-Up and Bareness Index) & $0.14-0.17$ \\
\hline NDBI (Normalised Difference Built-Up Index) & $0.071-0.11$ \\
\hline UI (Urban Index) & $0.14-0.20$ \\
\hline NDBaI (Normalised Difference Bareness Index) & $0.14-0.18$ \\
\hline
\end{tabular}

Built-up index provide some miss classifications in wetland areas due to similar reflectance properties. Table 2 shows the built-up areas as determined by each remote sensing transformation index. The result of the analysis showed that the total built-up area obtained from the EBBI transformation is 1623.08 ha $(14.65 \%)$. The estimated result is almost similar to the result derived through NDBI (14.92\%). However, the area of built-up land on Rajarhat block as determined by EBBI is $14.65 \%$ which is corresponds to $14.92 \%$ obtained through NDBI. The built-up area shown by the EBBI is smaller than that obtained from the NDBI, NDBaI and UI transformations (Figure 2).

Table 2: Areal distribution of built-up area derived from each type of remotely sensed index

\begin{tabular}{|l|c|c|}
\hline Remote sensing indices & Built up area (ha) & Proportion of the total area \\
\hline EBBI & 1623.08 & 14.65 \\
\hline NDBI & 1652.83 & 14.92 \\
\hline UI & 1942.72 & 17.53 \\
\hline NDBaI & 2525.44 & 22.79 \\
\hline
\end{tabular}


Ghosh K. D., Ch Mandal A., Majumder R., Patra P., Bhunia S. G.: Analysis for mapping of built-up area using remotely sensed indices

Fig. 2: Spatial mapping of built-up area of Rajarhat block, Barasat sadar sub-division
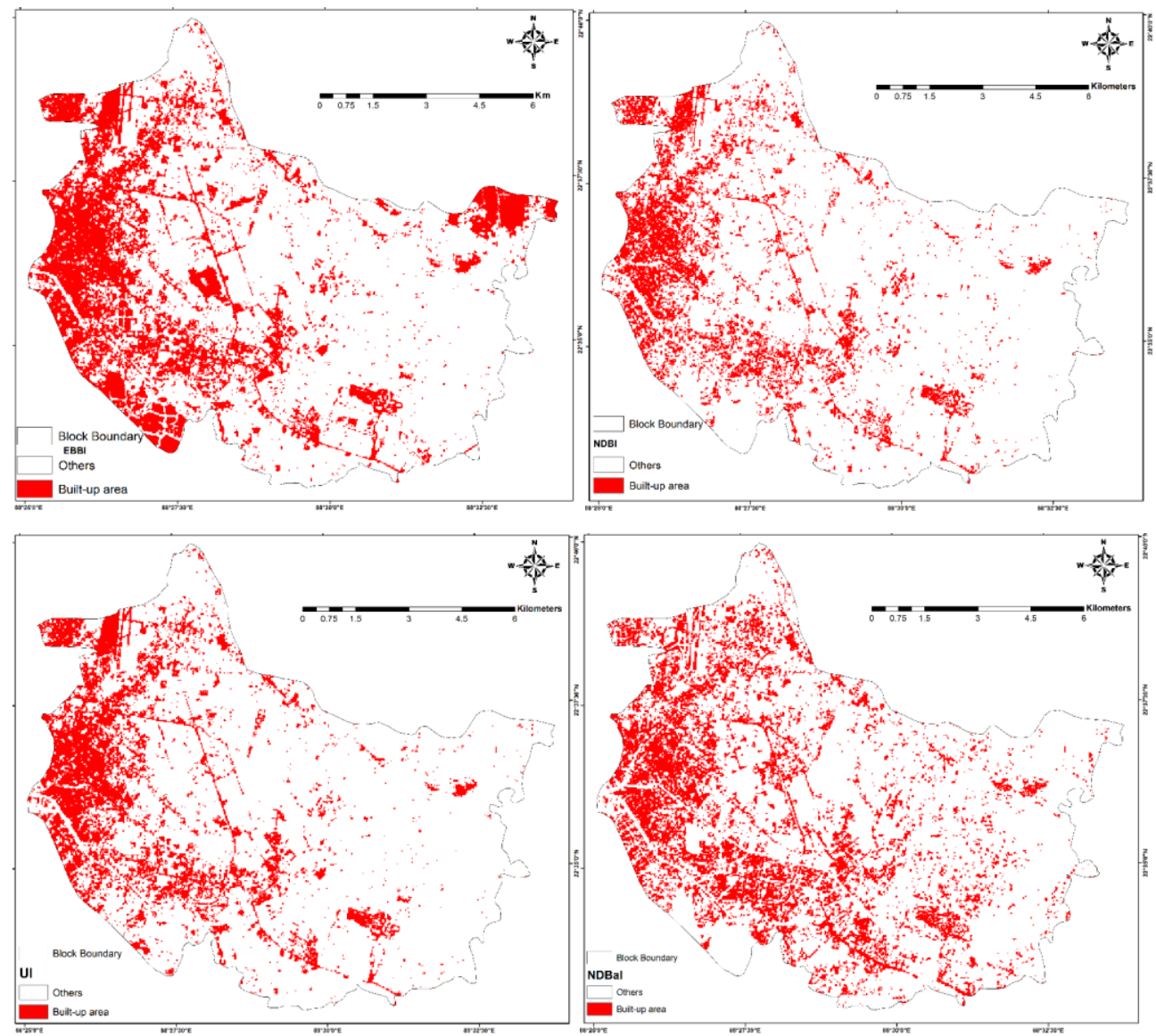

The accuracy levels pertaining to the percentage of built-up areas for each type of transformation index derived from Landsat OLI data are shown in Table 3. The built-up area determined using the NDBI and EBBI transformation was analogous to that determined via the OLI data which was supposed to characterize the actual built-up area. NDBI index is most reliable in this analysis, shows the highest overall accuracy of $76.45 \%$ and kappa accuracy of $57 \%$. The patterns of built-up area extraction were more in case of UI and NDBaI. This is because of incompetence of UI and NDBaI to discriminate between built-up and wet lands and most of the barren area in the contiguous parcel became mixed with the built-up area. The accuracy levels of EBBI is higher than the accuracy levels of the UI $(69.65 \%)$ and NDBaI (68.07\%) but marginally lower than that of the NDBI (Table 3). The NDBI can be utilized directly as highly accurate indices for mapping built-up areas using Landsat OLI data. 
Table 3: Accuracy assessment of the different remotely sensed urban indices

\begin{tabular}{|l|c|c|}
\hline Index & Overall accuracy & Kappa Accuracy \\
\hline EBBI & $74.08 \%$ & 0.53 \\
\hline NDBI & $76.45 \%$ & 0.57 \\
\hline UI & $69.65 \%$ & 0.41 \\
\hline NDBaI & $68.07 \%$ & 0.36 \\
\hline
\end{tabular}

\section{Relationship between the Transformed Remote Sensing Indices and the Percentage of Built-up Area}

Figure 3 shows the relationship between the percentage of built-up area and the transformation indices (EBBI, NDBaI, UI andNDBI). The linear equation and $\mathrm{R}^{2}$ value for each of the indices is indicated on the plot. The results shows a high degree of relationship between remote sending indices (EBBI, NDBaI, UI and NDBI) and the percentage of built-up areas (Figure 3). The NDBI results shows a high degree of correlation $\left(\mathrm{R}^{2}=0.9764\right.$, $\mathrm{P}<0.0001)$ wih the percentage of built-up area than the other remote sensing indices.

Fig. 3: Scatterplots of the built-up area percentage vs. the remote sensing transformation indices (a) EBBI, (b) NDBaI (c) UI and (d) NDBI

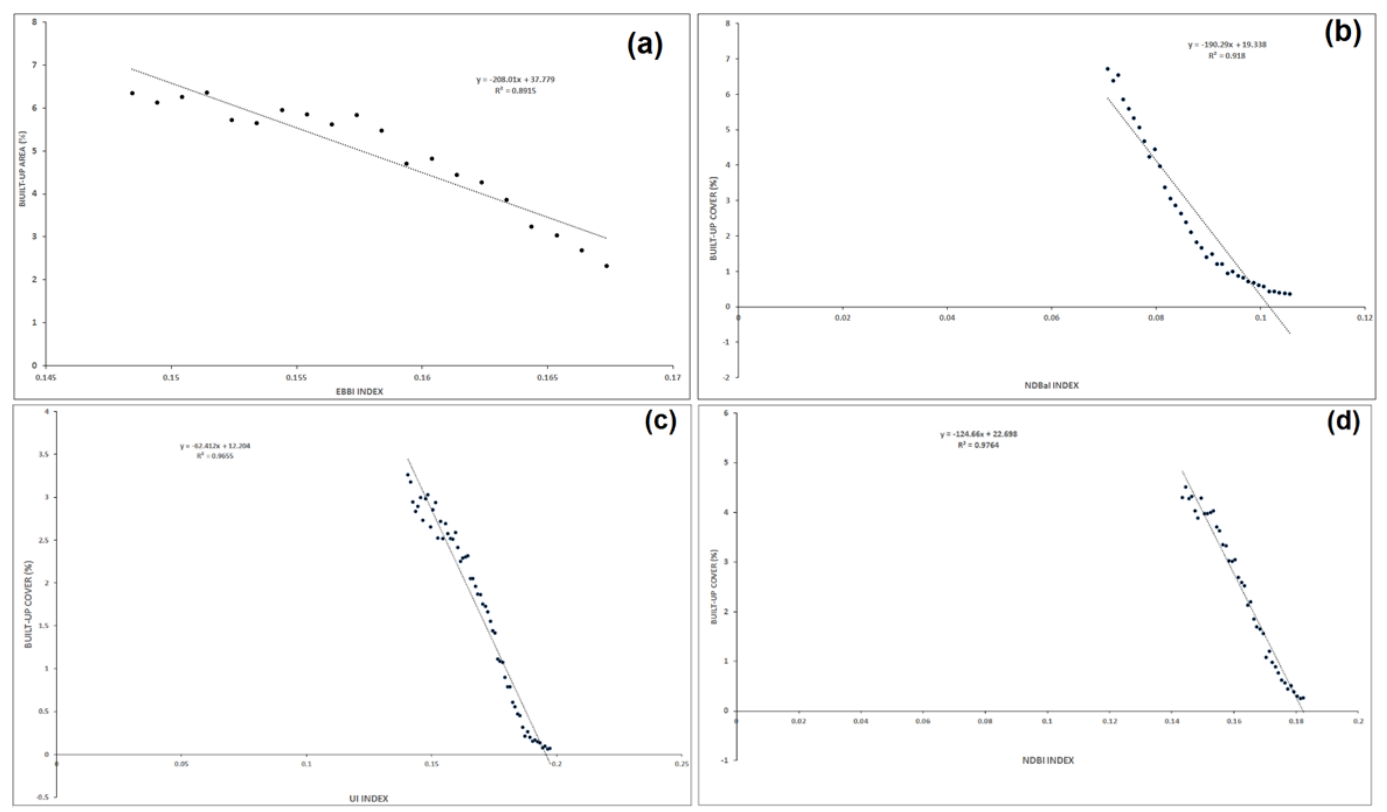

\section{DISCUSSION}

Urban remote sensing indices are generally used to distinguish built-up areas based on spectral values with a low level of accuracy because of high degree of homogeneity with the bare land and wetland areas. Earlier study conducted by Sen (2011) and Rahaman (2018) stated that there is an increase of population growth in Rajarhat municipality which is also corroborated with our study. However, utilization of EBBI and NDBI based on thermal 
Ghosh K. D., Ch Mandal A., Majumder R., Patra P., Bhunia S. G.: Analysis for mapping of built-up area using remotely sensed indices

infrared, shortwave infrared and near-infrared band of OLI data, can increase the accuracy of mapping built-up areas. Built-up areas exhibit higher degree of emissivity and heat conductivity than bare soil areas (Lesaignoux et al., 2009). The thermal infrared band (band ${ }_{11}$ of OLI) exhibit high emissivity in built-up areas, is one of the aspect for distinguishing between classes of land use (As-syakur et al., 2012). The spectral response of built-up areas showed a higher reflectance in the SWIR compared with the NIR wavelength range. The EBBI and NDBI reveals a better accuracy to discriminate the built-up areas with higher degree of correlation and lower statistical error. The research conducted by Sinha et al., (2016) and Bouhennache et al., (2015) also corroborated with our study. These two indices were found to be very effective in discerning built-up areas which is one of the main confines of applying built-up area indices based on remotely sensed indices.

The high amount of land heterogeneity in built-up land areas ensued in low level of accuracy. Yüksel et al., (2008) stated that precise map processing in urban landscapes in further intricate by surface heterogeneity. The UI and NDBaI indices produced the built-up areas and simultaneously demarcated the wetland areas that may be due to the higher reflectance in SWIR compared with the NIR wavelength range (As-syakur et al., 2012). However, in urban areas with heterogeneous landscape, these indices are not always relevant.

Data from built up areas are very important for determining correlations between land use and environmental conditions (Chen et al., 2009). All the indices could not perfectly differentiate built-up land because of the similar spectral response with the other land use and land cover classes, like bare soil, wet land areas. However, the NDBI were found to be superior to the other indices in distinguishing built-up areas from OLI data. It predictable that NDBI could be employed in numerous applications concomitant with the utilization of the geospatial data, particularly in the subject of urban remote sensing.

\section{CONCLUSION}

The remote sensing indices were applied in Rajarhat block (Barasat sadar sub-division) to determine the built-up areas in an urban area. The NDBI and EBBI index that uses the NIR, SWIR and TIR bands simultaneously for mapping built-up areas. The NDBI showed an average accuracy level of $76.45 \%$ respectively which is higher than those of UI and NDBaI. The proposed method has some limitation, like heterogonous landscape with drier vegetation and missed land still problematic with respect to sub-dividing urban areas. Enlightening the spatial resolution may expand the exactness of remote sensing in seizing small objects in urban areas. The technique was found very meek to calculate and easy to contrivance; nevertheless, it necessities more challenging primarily for more multifarious mixed landscapes in terms of discriminating land cover classes. Nevertheless, coalescing these indices could improve the classification accuracy and may attain better results. Finally, NDBI was projected to map built-up areas based on Landsat8 OLI bands and outcome of this study would countenance urban planner to recognize and estimate urban growth for sustainable practice of urban land system.

\section{ACKNOWLEDGEMENT}

We thankful to the Earth Explorer community for archiving satellite data. 


\section{REFERENCES}

As-syakur, A.R., Adnyana, W.S., Arthana, W., Nuarsa, W. (2012). Enhanced Built-Up and Bareness Index (EBBI) for Mapping Built-Up and Bare Land in an Urban Area. Remote Sens. 2012, 4, pp. 2957-2970.

Bouhennache, R., Bouden, T., Taleb, A.A., Chaddad, A. (2015). Extraction of urban land features from TM Landsat image using the land features index and Tasseled cap transformation. Recent Advances on Electroscience and Computers. 2015, pp. 142-147, ISBN: 978-1-61804-290-3.

Chen, W.B., Liu, S.Y., Yu, D., Zou, Q.M. (2009). Assessment of land use environmental impacts in urban built-up area: a case study in main built-up area of Nanchang City. Ying Yong Sheng Tai Xue Bao. 2009, 20(7), pp.1747-52.

He, C., Shi, P., Xie, D., Zhao, Y. (2010). Improving the normalized difference built-up index to map urban built-up areas using a semiautomatic segmentation approach. Remote Sensing Letters , 2010, 1(4).

Kawamura, M., Jayamana, S., Tsujiko, Y. (1996). Relation between social and environmental conditions in Colombo Sri Lanka and the urban index estimated by satellite remote sensing data. Int. Arch. Photogramm. Remote Sens. 1996, 31 (Part B7), pp. 321-326. Kumari, A., Shekhar, S. (2016). Quantifying Spatio-Temporal Changes in Urban Area of Gulbarga City Using Remote Sensing and Spatial Metrics. IOSR Journal of Environmental Science, Toxicology and Food Technology 2016, 10(5), pp. 44-49.

Lesaignoux, A, Fabre, S., Briottet, X., Olioso, A. (2006). Influence of surface moisture on spectral reflectance of bare soil in the $0.4-1.5 \mu \mathrm{m}$ domain. In Proceedings of the $6^{\text {th }} E A R S e L$ SIG IS Workshop, Tel-Aviv, Israel, 16 - 19 March, 2006 (p. 6).

Li, H., Wang, C., Zhong, C., Su, A., Xiong, C., Wang, J., Liu, J. (2017). Mapping Urban Bare Land Automatically from Landsat Imagery with a Simple Index. Remote Sens. 2017, 9, 249; doi:10.3390/rs9030249.

Melesse, A.M., Weng, Q. S., Thenkabail, P., Senay, G.B. (2007). Remote Sensing Sensors and Applications in Environmental Resources Mapping and Modelling. Sensors (Basel, Switzerland). 2007; 7(12), pp. 3209-3241.

Middey, A., Kaware, P.B. (2016). Disposition of Lightning Activity Due to Pollution Load during Dissimilar Seasons as Observed from Satellite and Ground-Based Data. Climate 2016, 4(2), 28; doi:10.3390/cli4020028.

Paul, S., Chatterjee, K. (2012). Urbanisation and Consistency Measurement: A Study on District of North 24 Parganas, West Bengal, India. Archives of Applied Science Research, 2012, 4 (5), pp. 2052-2067.

Rahaman, M. (2018). Urban Population Growth in the Municipalities of North 24 Parganas: A Spatio-Temporal Analysis. World Wide Journal of Multidisciplinary Research and Development, 2018; 4(3), pp. 68-73.

Rikimaru, A.; Miyatake, S. (1997). Development of Forest Canopy Density Mapping and Monitoring Model using Indices of Vegetation, Bare soil and Shadow. In Proceeding of the 18th Asian Conference on Remote Sensing (ACRS) 1997 (p.3), Kuala Lumpur, Malaysia, 2025 October 1997.

Sen, S. (2011). Effect of Urban Sprawl on Human Habitation in Urban Fringe and Peri-Urban Areas in Kolkata Metropolitan Area. Institute of Town Planners, 2011, pp. 58 66. 
Ghosh K. D., Ch Mandal A., Majumder R., Patra P., Bhunia S. G.: Analysis for mapping of built-up area using remotely sensed indices

Sinha, P., Verma, N.K., Ayele, E. (2016). Urban Built-up Area Extraction and Change Detection of Adama Municipal Area using Time-Series Landsat Images. International Journal of Advanced Remote Sensing and GIS. 2016, 5(8), pp. 1886-1895.

Sukristiyanti, R., Suharyadi, Jatmiko, R.H. (2007). Evaluasi Indeks Urban pada citra Landsat Multitemporal dalam ekstraksi kepadatan bangunan. Jurnal Riset Geologi dan Pertambangan 2007, 17, pp. 1-10.

Tamilenthi, S., Punithavathi, J., Baskaran, R., ChandraMohan, K. (2011). Dynamics of urban sprawl, changing direction and mapping: A case study of Salem city, Tamilnadu, India. Archives of Applied Science Research, 2011, 3 (1), pp. 277-286.

Weng, L., Lub, D., Schubring, J. (2004). Estimation of land surface temperature-vegetation abundance relationship for urban heat island studies. Remote Sensing of Environment 89 (2004), pp. $467-483$.

Weng, Q., Hu, X., and Lu, D. (2008). Extracting Impervious Surface from Medium Spatial Resolution Multispectral and Hyperspectral Imagery: A comparison. International Journal of Remote Sensing. 2008. 29 (11), pp. 3209-3232.

$\mathrm{Xu}, \mathrm{H}$. (2008). A new index for delineating built-up land features in satellite imagery. Int. J. Remote Sens. 2008, 29, pp. 4269-4276.

Yüksel, A., Akay, A.E., Gundogan, R. (2008). Using ASTER imagery in land use/cover classification of eastern Mediterranean landscapes according to CORINE land cover project. Sensors 2008, 8, pp. 1237-1251.

Zha, Y., Gao, J., Ni, S. (2003). Use of normalized difference built-up index in automatically mapping urban areas from TM imagery. Int. J. Remote Sens. 2003, 24, pp. 583-594.

Zhao, H.M., Chen, X.L. (2005). Use of Normalized Difference Bareness Index in Quickly Mapping Bare Areas from TM/ETM+. In Proceedings of 2005 IEEE International Geoscience and Remote Sensing Symposium (pp. 1666-1668), Seoul, Korea, 25-29 July 2005; Volume 3. 